\title{
A Note on the Comparison of Rocket and Estimated Geostrophic Winds at the 10-mb Level
}

\author{
MARVIN D. KAYS \\ U.S. Army Electronics Research and Development Activity, White Sands Missile Range, N. Mex.
}

5 March 1965 and 26 August 1965

\section{Introduction}

The $10-\mathrm{mb}$ surface is the highest level for which height contour and temperature analyses are routinely available. These analyses have been prepared under the direction of Dr. Richard Scherhag at the Free University of Berlin under the sponsorship of the U. S. Army.

It is apparent that analyses for the 10-mb level cannot be as accurate as those for lower levels, say at $100 \mathrm{mb}$, because data are scarce and often of poor quality owing to various instrumental errors that become especially serious at these high levels. Furthermore, data that do not extend to the $10-\mathrm{mb}$ level are often extrapolated upward by use of the hydrostatic equation.

Since 1959 wind and temperature data from rocketsondes have become available, extending the region from which data are gathered from $30 \mathrm{~km}$ to levels in excess of $60 \mathrm{~km}$. The data are derived from radar- tracked sensors, mostly parachute or chaff types, that have been ejected from the rocket near its apogee in flight. Most of the agencies contributing data are members of the Inter-Range Instrumentation Group which, through its Meteorological Rocket Network Committee, coordinates the agencies' activities within the Network. The data are published in monthly volumes and furnish a means of making some comparisons between the geostrophic winds computed from the $10-\mathrm{mb}$ maps and the reported rocket winds at that level.

The purpose of this note is to summarize some comparisons that have been made between the $10-\mathrm{mb}$ geostrophic winds and winds measured by rocketsondes at the same altitude, location, and at approximately the same time. The comparisons should establish to some extent the degree of reliability that can be placed in the usage of Scherhag's maps for computing derived quantities such as geostrophic winds, vorticity, temperature advections, energy computations, etc. 


\section{Procedure}

Using Scherhag's maps and taking into account contours separated by 160 geopotential meters, a polar sterographic projection true at $60 \mathrm{~N}$, and a map scale of $1: 125,000,000$, the geostrophic winds were computed from the formula,

$$
C=\frac{311}{N(\sin \phi)(1+\sin \phi)},
$$

where $C=$ geostrophic wind speed in knots, $\phi=$ latitude of the rocketsonde station, and $N=$ distance between contours measured in millimeters.

Since very few of the rocket firings coincided with the map times, it was necessary to use linear interpolation to approximate the geostrophic winds from the 0000 GMT maps to correspond with the time of the rocket firing.

One hundred and forty-seven comparisons were made from data collected at White Sands Missile Range, New Mexico; Wallops Island, Virginia; and Fort Greely, Alaska, during the months of January, March, July, August, November, and December of 1962 and 1963; February 1962; June 1963; and January and February 1964. The omission of other months was not intentional, but was due to the fact that data obtained during these months were usually in the regions of weak contour gradients and probably not geostrophic. No corrections for the curvature of contour lines have been made, but the cases have been limited to small curvatures. No attempt was made to smooth the wind profiles as found in the Meteorological Rocket Network data publications.

\section{Results}

The relative deviation (Godson, 1950) of the rocket wind vector from the computed geostrophic wind vector was evaluated as the nondimensional quantity $|\mathbf{R}-\mathbf{G}| /|\mathbf{R}|$, where $\mathbf{R}$ is the rocket wind vector and $\mathbf{G}$ is the estimated geostrophic wind vector. This was computed as follows:

$$
\frac{|\mathbf{R}-\mathbf{G}|}{|\mathbf{R}|}=\frac{\left[\left(u_{r}-u_{g}\right)^{2}+\left(v_{r}-v_{g}\right)^{2}\right]^{\frac{1}{2}}}{\left(u_{r}{ }^{2}+v_{r}{ }^{2}\right)^{\frac{1}{2}}}
$$

where $u$ and $v$ are the wind components, and are positive for winds from the west and south, respectively. The mean relative deviation was found to be 39 per cent, but it must be remembered that extremely large deviation values can be obtained when small vector magnitudes are used. To take this into account, the vector magnitudes were divided into increments of $20 \mathrm{kt}$ up to $100 \mathrm{kt}$, and then for all greater than $100 \mathrm{kt}$, with the average relative deviation computed for the corresponding increments (Fig. 1).

The vector differences between the rocket and the estimated geostrophic winds were examined, and the

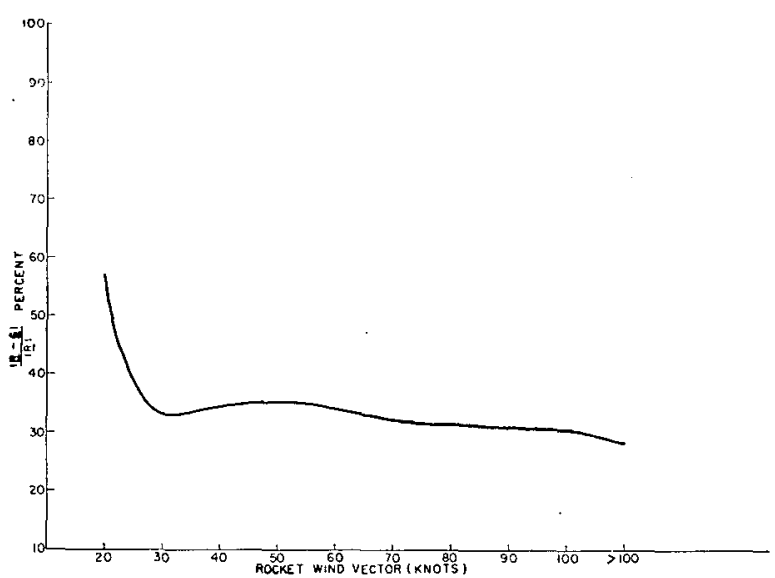

FIG. 1. Relative deviation between the rocket wind vector and the estimated geostrophic wind vector.

results are listed in Table 1 . The arithmetic mean of these vector differences was $+5.5 \mathrm{kt}$ which signifies that the mean rocket wind is larger than the geostrophic wind. The differences of the wind speed were examined and these results are shown in Table 1 . Since results

TABLE 1. Comparison of the observed wind $(\mathbf{R})$ and the estimated geostrophic wind $(\mathbf{G})$ of different studies at different levels.

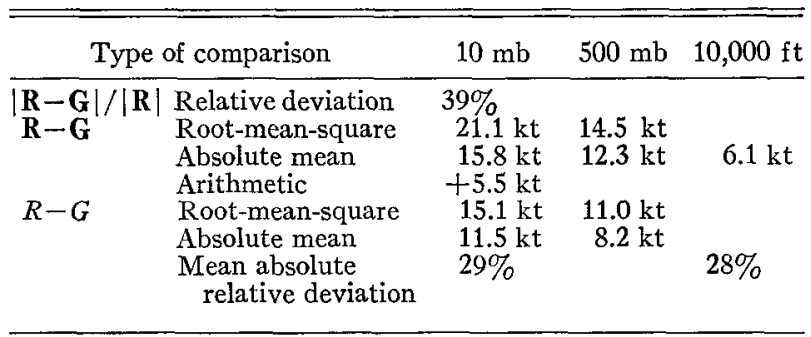

similar to Fig. 1 were obtained when the wind speed was broken into increments they were not plotted.

The results obtained here compare favorably with earlier studies, even though they were for lower levels. Bannon (1949) compared 161 cases at the $500-\mathrm{mb}$ level and Godson (1950) compared 618 cases at the 10,000-ft level, and some of their results are shown in Table 1.

\section{Conclusion}

Scherhag's 10-mb maps, in spite of scarce data, yield geostrophic wind speeds that compare favorably with actual measurements that were not available when the analyses were done. When working with the $10-\mathrm{mb}$ maps, more accuracy could be obtained if the data were confined to cases where the wind speed is $20 \mathrm{kt}$ or more. Generally speaking, there is better agreement between the rocket and calculated geostrophic wind as the wind speed increases.

Acknowledgments. I wish to thank Dr. Richard A. Craig of Florida State University for his helpful comments and suggestions. 


\section{REFERENCES}

Banuon, J. K., 1949: Angular deviation of the wind from the isobars at Liverpool. Quart. J. R. Meteor. Soc., 75, 131-146.

Godson, W. L., 1950: A study of the deviations of wind speeds and directions from geostrophic values. Quart. J. R. Meteor. Soc., 76, 3-15.

Inter-Range Instrumentation Group, Meteorological Working Group: Data reports of the Meteorological Rocket Network, IRIG-MWG. Nos, 10-12, 15-17, 19, 22-25, 27-30. Available from Secretariat, Range Commanders Council, ATTN: STEWS-SA-S-RCL, White Sands Missile Range, New Mexico 88002.

Scherhag, R., et al., 1962-1964: Preliminary daily Northern Hemisphere 10-millibar synoptic weather maps. Meteorologische Abhandlungen, 26, Heft 1, 3, 4, 1962; 40, Heft 1, 2, 3, 4, 1963; 49, Heft 1, 1964. Institut fur Meteorologie und Geophysik der Freien Universitat Berlin, U. S. Army Contract No. DA-91-591-EUC-3288-OI, 360565-B. 